\title{
ILSI Southeast Asia symposium: prevalence, risk factors, and actions to address gestational diabetes in selected Southeast Asian countries
}

\author{
Maria Sofia Amarra ${ }^{1}{ }^{1}$ - Mary Foong-Fong Chong ${ }^{2} \cdot$ Vitaya Titapant $^{3}$ - Charintip Somprasit ${ }^{4}$ - Jossie Rogacion ${ }^{5}$. \\ Rima Irwinda ${ }^{6}$. Trang Nguyen Khanh Huynh ${ }^{7} \cdot$ Sivalingam Nalliah $^{8}$
}

Received: 21 June 2020 / Revised: 16 November 2020 / Accepted: 7 December 2020 / Published online: 2 February 2021

(c) The Author(s) 2021. This article is published with open access

\section{Introduction}

Gestational diabetes mellitus (GDM) is increasing, particularly in Southeast Asia. This paper presents findings from a symposium organized by the International Life Sciences Institute Southeast Asia (ILSI SEA) which discussed the growing issue of gestational diabetes and how it can be addressed in the region. GDM together with diabetes in pregnancy (DIP) both fall under the definition of hyperglycemia in pregnancy [1]. GDM is defined as diabetes diagnosed for the first time during pregnancy mostly after 24 weeks gestation. DIP is defined as pregnant women having higher oral glucose tolerance test (OGTT) results [1]. Table 1 shows the WHO criteria that distinguish GDM and DIP [2].

Women with hyperglycemia in pregnancy have a higher risk of developing diabetes over 15 years after the index pregnancy. It was estimated that 75-90\% of cases of hyperglycemia in pregnancy are GDM [1]. Although data are lacking, GDM prevalence is thought to parallel the

These authors contributed equally: Maria Sofia Amarra, Sivalingam Nalliah

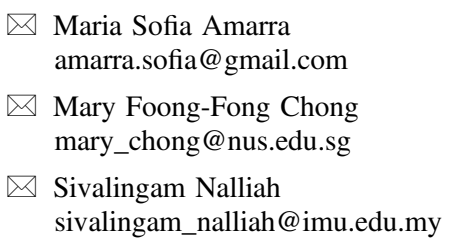

Maria Sofia Amarra

amarra.sofia@gmail.com

$\triangle$ Mary Foong-Fong Chong

mary_chong@nus.edu.sg

$\triangle$ Sivalingam Nalliah sivalingam_nalliah@imu.edu.my

1 Department of Food Science and Nutrition, College of Home Economics, University of the Philippines Diliman, Quezon, Philippines

2 Saw Swee Hock School of Public Health, National University of Singapore, Singapore, Singapore rising incidence of type 2 diabetes mellitus in the background population [1]. Table 2 shows the 2019 prevalence of diabetes and undiagnosed diabetes in Southeast Asian countries [1].

The objectives of this ILSI SEA symposium were to: (i) assess the prevalence of GDM in selected countries (Malaysia, Singapore, Indonesia, Thailand, Philippines, Vietnam) and identify nutritional and other risk factors; (ii) identify country actions to address GDM and challenges in implementing these actions; (iii) recommend measures to prevent/reduce the prevalence of GDM in Southeast Asia.

\section{Results}

\section{Prevalence of GDM in selected Southeast Asian countries}

Figure 1 shows the prevalence of GDM in selected Southeast Asian countries based on existing data.

Prevalence estimates ranged from $1.7 \%$ to $25 \%$, based on varying criteria. Only Singapore and Malaysia have national estimates for GDM prevalence. Vietnam, Indonesia,

3 Department of Obstetrics and Gynecology, Faculty of Medicine, Siriraj Hospital Mahidol University, Bangkok, Thailand

4 Department of Obstetrics and Gynecology, Faculty of Medicine, Thammasat University, Bangkok, Thailand

5 Department of Pediatrics, University of the Philippines, Manila, Philippines

6 Department of Obstetrics and Gynecology, Faculty of Medicine, Universitas Indonesia, Jakarta, Indonesia

7 Department of Obstetrics and Gynecology, Pham Ngoc Thach University of Medicine, Ho Chi Minh, Vietnam

8 Division of Obstetrics \& Gynaecology, Clinical School, International Medical University, Seremban, Malaysia 
Table 1 WHO criteria for GDM and DIP [2].

\begin{tabular}{|c|c|c|}
\hline & Gestatational diabetes mellitus (GDM) & Diabetes in pregnancy (DIP) \\
\hline $\begin{array}{l}\text { Requirement for } \\
\text { classification }\end{array}$ & $\begin{array}{l}\text { One or more of the following criteria are met at } \\
\text { any time in pregnancy }\end{array}$ & $\begin{array}{l}\text { One or more of the following criteria are met (for both } \\
\text { pregnant and non-pregnant women) }\end{array}$ \\
\hline Fasting plasma glucose & $5.1-6.9 \mathrm{mmol} / \mathrm{L}(92-125 \mathrm{mg} / \mathrm{dL})$ & $\geq 7.0 \mathrm{mmol} / \mathrm{L}(126 \mathrm{mg} / \mathrm{dL})$ \\
\hline 1-h plasma glucose & $\begin{array}{l}\geq 10.0 \mathrm{mmol} / \mathrm{L}(180 \mathrm{mg} / \mathrm{dL}) \text { following a } 75 \mathrm{~g} \text { oral } \\
\text { glucose load }\end{array}$ & - \\
\hline 2-h plasma glucose & $\begin{array}{l}8.5-11.0 \mathrm{mmol} / \mathrm{L}(153-199 \mathrm{mg} / \mathrm{dL}) \text { following a } \\
75 \mathrm{~g} \text { oral glucose load }\end{array}$ & $\geq 11.1 \mathrm{mmol} / \mathrm{L}(200 \mathrm{mg} / \mathrm{dL})$ following a $75 \mathrm{~g}$ oral glucose load \\
\hline Random plasma glucose & $\mathrm{n} / \mathrm{a}$ & $\geq 11.1 \mathrm{mmol} / \mathrm{L}(200 \mathrm{mg} / \mathrm{dL})$ \\
\hline
\end{tabular}

- no established criteria for the diagnosis of diabetes based on the 1-h post-load value, $n / a$ not applicable.

Table 2 Age-adjusted comparative prevalence of diabetes in adults aged 20,979 years (2019) by country [1].

\begin{tabular}{lll}
\hline & $\begin{array}{l}\text { Diabetes age-adjusted } \\
\text { comparative prevalence } \\
(\%) \text { in adults 20-79 year } \\
(95 \% \text { CI })\end{array}$ & $\begin{array}{l}\text { Number of adults 20-79 } \\
\text { year with undiagnosed } \\
\text { diabetes in 1000 s (95\% CI) }\end{array}$ \\
\hline Malaysia & $16.7(14.9-19.2)$ & $1841.3(1652.2-2125.9)$ \\
Brunei & $13.3(9.3-17.6)$ & $18.7(14.0-24.3)$ \\
Philippines & $7.1(5.6-8.9)$ & $2662.3(2122.7-3360.4)$ \\
Thailand & $7.0(5.4-8.1)$ & $1868.0(1444.1-2145.2)$ \\
Cambodia & $6.3(4.9-11.0)$ & $268.1(199.5-530.4)$ \\
Indonesia & $6.3(5.4-6.8)$ & $7870.1(6789.6-8509.8)$ \\
Lao PDR & $6.3(4.9-11.0)$ & $102.3(78.2-192.8)$ \\
Vietnam & $6.0(4.9-8.1)$ & $2017.7(1646.4-2670.9)$ \\
Singapore & $5.5(4.7-6.3)$ & $346.0(300.8-389.0)$ \\
Myanmar & $3.9(3.0-5.9)$ & $684.7(537.6-1001.6)$ \\
\hline
\end{tabular}

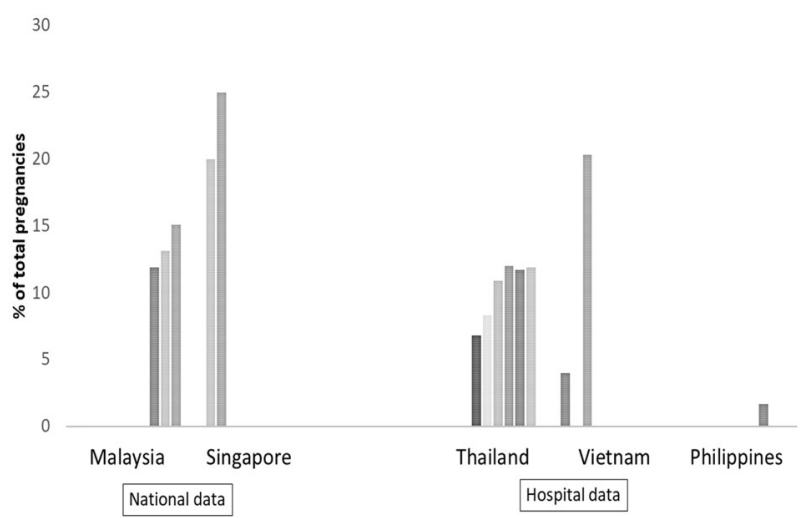

Fig. 1 Prevalence of GDM in Southeast Asian countries based on existing data.

Thailand, and the Philippines only have hospital-based data. Based on national data, Singapore has a higher prevalence of GDM than Malaysia (Fig. 1). Based on hospital data, Vietnam has the highest prevalence, followed by Thailand, and lastly the Philippines. Using hospital data, Purnamasari et al. [3] reported that the prevalence of GDM in Indonesia ranged from $1.9 \%$ to $3.6 \%$ but the period was not specified. All countries showed an increasing trend in GDM prevalence over time.

Limitations of the data are the fact that each country used different criteria to diagnose GDM which limits comparability. Most had small sample sizes derived from hospital data. There is no uniformity in employing criteria for the diagnosis of GDM among the nations. The International Association of Diabetes and Pregnance Study Groups (IADPSG), American Diabetes Association (ADA), and WHO criteria were employed. Malaysia, Singapore, and Vietnam reported higher prevalence when IADPSG criteria were used, compared to other criteria.

\section{Nutritional risk factors for GDM in selected Southeast Asian countries}

Table 3 summarizes the nutritional and non-nutritional risk factors for GDM based on existing evidence.

i. Anthropometric measurement. In all countries, preconception overweight and obesity were important risk factors for GDM [4-6]. The lowest BMI level associated with GDM occurred among Vietnamese women (BMI $\geq 21$ ), while the highest level occurred among Malaysian women (BMI > 27).

ii. Dietary intake. In Singapore and Indonesia, dietary patterns, as well as specific foods and nutrients, were shown to be risk factors for GDM. In Singapore, the Growing Up in Singapore Towards Healthy Outcomes (GUSTO) cohort study identified two key dietary patterns [7]. The first dietary pattern was a vegetable, fruits, rice-based pattern characterized by high consumption of vegetables, fruits, whole grain bread, nuts and seeds, white rice, and lower consumption of carbonated and sweetened drinks, burgers, meat, fried potatoes. The second dietary pattern was seafood, noodle, and soup-based pattern characterized by high consumption of soup, fish and seafood products, noodles, red meat, seafood, soya- 


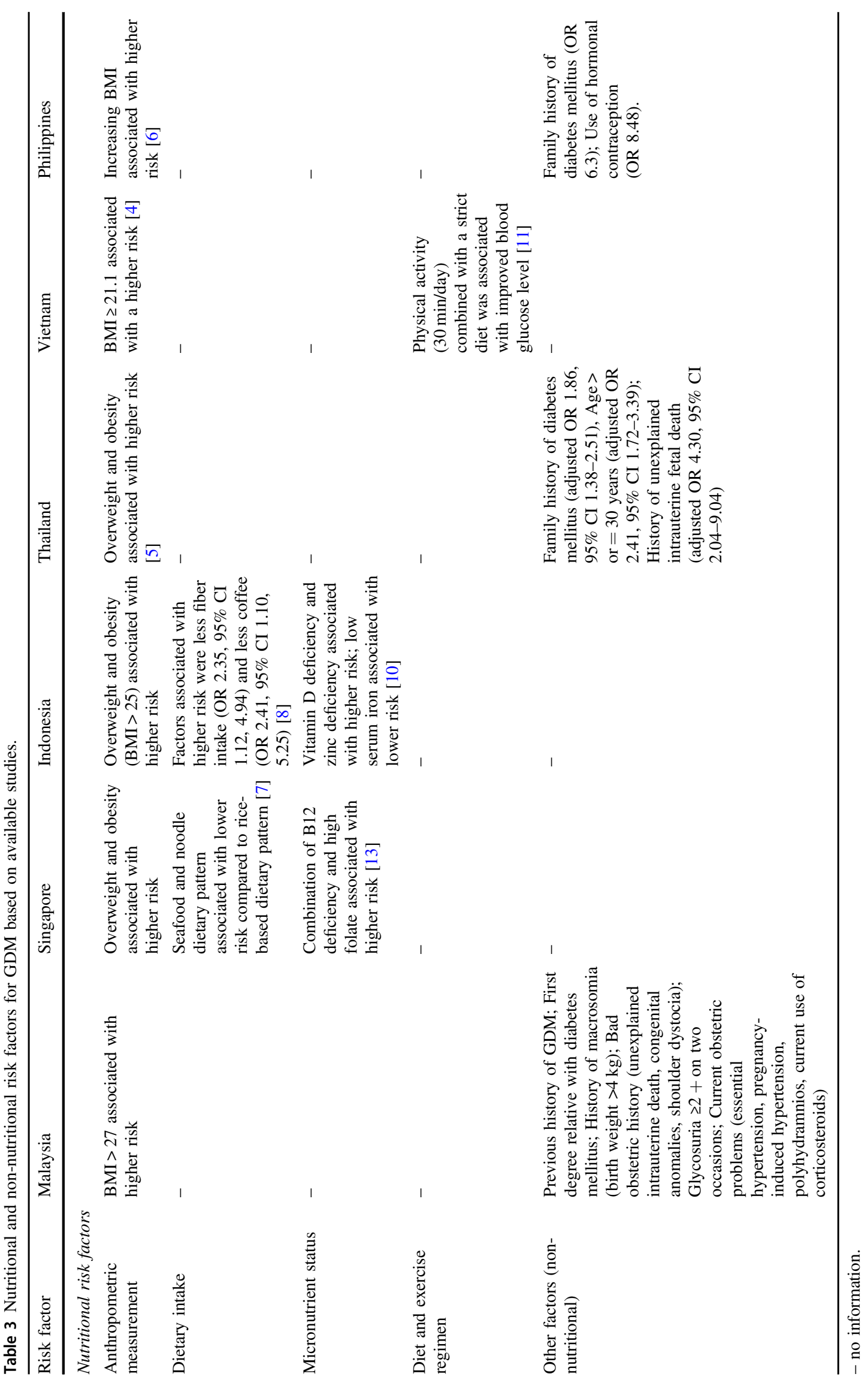


based gravy, and lower consumption of legumes/ pulses, ethnic bread, rice, curry gravy, other grains. Mothers following the seafood and noodle dietary pattern had a lower risk of GDM compared to those consuming the rice-based pattern.

In Indonesia, a retrospective study [8] showed that the risk of prediabetes and GDM increased among respondents with a history of less fiber consumption (OR 2.35, 95\% CI 1.12, 4.94) and less coffee consumption (OR 2.41, 95\% CI 1.10, 5.25).

iii. Micronutrient status. The Singapore GUSTO study showed that the combination of high folate and vitamin B12 (cobalamin) deficiency was associated with higher GDM risk, compared to those with insufficient B12 and low concentrations of folate. If women were sufficient in B12, no significant associations with the risk of GDM were observed with increasing folate concentrations. The results suggest that an imbalance in the two B-vitamins may be responsible for glucose intolerance. Adjustment for pre-pregnancy BMI attenuated the effect of different concentrations of B12 on the prevalence of GDM, indicating that BMI explains part of the association of vitamin B12 with plasma glucose concentrations and GDM.

The exact mechanism of this phenomenon is unclear. One theory is that when B12 is insufficient, the conversion of 5-methyltetrahydrofolate to tetrahydrofolate is inhibited. This impairs the production of purines and pyrimidines for DNA/RNA synthesis, resulting in impaired mitochondrial DNA which in turn is correlated with the development of insulin resistance. Insufficient B12 was also shown to increase adiposity during pregnancy, which may also impair insulin signaling [9]. These findings suggest that other micronutrient deficiencies should be considered when supplementing mothers during pregnancy and that the combination of high folate with low B12 can lead to metabolic consequences.

In Indonesia, Wibowo et al. [10] examined 234 pregnant women in the first trimester of pregnancy. Prevalent micronutrient deficiencies were vitamin A (69.7\% of women), vitamin D (99.6\%), and zinc $(81.2 \%)$. Vitamin D and zinc deficiencies were shown to increase the risk of GDM.

iv. Combined diet and exercise regimen. Trang et al. [11] demonstrated the beneficial effect of combined physical activity (walking $30 \mathrm{~min} /$ day) and medical nutrition therapy (MNT) (hospital daily menu only with no other food and drinks) on blood sugar levels in Vietnamese pregnant women with GDM. The proportion of women with stable blood glucose levels increased from $71.2 \%$ to $87.2 \%$ after 3 and 7 days, respectively $(\mathrm{RR}$ for blood glucose stability $=2.67$, $95 \%$ CI 1.03, 6.92; $p<0.05)$.

\section{Challenges in addressing GDM in Southeast Asia}

At the regional level, the following common problems in the different countries were raised:

- Lack of pre-conceptual screening. Identifying and managing type 2 diabetes is end-stage management. Strategies to identify at-risk women should be put in place earlier.

- Maternal weight gain and postpartum weight retention. Obesity is common. Obese mothers have larger babies (almost double the size of normal weight) and a higher risk of preterm delivery due to complications associated with obesity.

- Lack of longitudinal care. The current "vertical point of care" approach is focused on reducing mortality and morbidity of the newborn and does not address longterm consequences in both mother and child.

- Lack of emphasis on MNT. MNT is the cornerstone in GDM management. The goal of MNT is to provide adequate calories and nutrients to meet the needs of pregnancy consistent with maintaining normoglycemia. However, there is no specific recommended dietary approach to manage GDM.

- Absence of national GDM guidelines and inadequate implementation of existing national guidelines, if any. Despite the presence of existing national guidelines for management in many countries, these are not closely adhered to across all health facilities within countries due to lack of manpower, budget, and low awareness of GDM among doctors and frontline health workers. In the absence of national guidelines, adherence to WHO guidelines were recommended.

\section{Discussion}

The following measures were proposed to prevent/reduce GDM in the region.

\section{Adoption of universal screening and use of common screening methods and diagnostic criteria}

A consensus is needed for common criteria to define GDM among Southeast Asian women. But whether this is possible to implement will require further studies as certain screening methods increased the prevalence of GDM, resulting in a heavy workload for the health care system. It was suggested that countries adopt the standard practice of 
having an OGTT during the second and third trimester and then once identified, refer to a dietitian for MNT and a physiotherapist for antenatal exercise. Universal screening rather than the selective screening of high-risk groups was recommended, to capture women without risk factors [12].

\section{Collection of nationwide epidemiological data by Southeast Asian countries}

Except for Singapore and Malaysia, the rest of the countries do not have adequate data on the prevalence of GDM at the national level. Epidemiological data in the region can be established if a common definition for GDM is developed and Southeast Asian countries agree on how to screen and diagnose GDM. A national policy mandating doctors to report GDM cases to a national health registry or database will help. The registry can include BMI, family history, past medical history, etc. These data will allow countries to define the patterns, determinants, and distribution of disease. From there, plans can be made on how to address the problem of GDM. An ASEAN study to show the long-term health impact of GDM on the offspring is also needed.

\section{Implementation of the following actions at different stages}

- During pre-conception, women should be encouraged to achieve an ideal BMI. Pregnancies should be planned, and pre-existing diabetes well-optimized prior to a planned pregnancy. Efforts are needed to increase awareness among mothers and families to ensure that the prevention of GDM is taken seriously. Currently, there is no clear guidance for mothers regarding the prevention of GDM.

- During pregnancy, women should be taught about proper dietary intake to prevent excessive gestational weight gain and weight gain monitoring. Timing and mode of delivery should be planned to reduce perinatal mortality and sudden intrauterine demise.

- After delivery, women should be encouraged to practice exclusive breastfeeding for the first six months and to regain the pre-pregnancy weight. Other practices that need to be promoted are self-monitoring of blood glucose, MNT, regular exercise, antenatal classes, contraception, pregnancy spacing, and health care between pregnancies.

\section{Modify cultural beliefs and practices that may contribute to GDM}

Some ethnic groups believe that pregnancy induces a craving for sugary foods. E.g., Chinese women may consume red date drinks frequently to improve blood circulation and increase iron. These drinks may contain high levels of sugar which can affect blood glucose level, thereby contributing to GDM.

Increase interventions to promote health literacy and diabetes education, empowerment of women (through adult education), self-care about GDM, knowledge of the intergenerational incidence of DM. Education should emphasize the importance of a healthy lifestyle at all levels, from the young to the elderly population, and included it in the school curriculum.

\section{Intensify research in the following areas}

- The role of iron supplementation on the risk of iron toxicity and GDM among women with genetic hemoglobin disorders, particularly in countries where the condition is prevalent.

- The role of micronutrient deficiencies in relation to GDM and whether ethnic-specific micronutrient requirements are needed.

- The role of MNT in GDM management. Local research based on ethnic diversity and food habits should be carried out for the development of individualized meal plans. Countries should develop local dietary guidelines, diet therapy, and culturally appropriate meal plans for GDM based on local research rather than simply adopting findings from non-Asian populations.

- National figures on normal weight gain in pregnancy are lacking. Appropriate gestational weight gain in Asian women need to be determined, depending on pre-pregnancy BMI. Factors that influence postpartum weight and ways to lose excess weight should be studied. In Malaysia and Vietnam, the majority of mothers retained their weight at 6-months postpartum.

- Determinants of health status in pre-pregnant and pregnant Asian women, the nutrigenomics and nutrigenetics of women likely to develop GDM.

- Effective nutrition education and communication strategies to achieve behavior change, including culturally appropriate approaches that encourage overweight women to come for consultation without increasing pressure or reducing their self-esteem.

\section{Conclusion}

The ILSI symposium highlighted the need for urgent actions to address the growing problem of GDM in Southeast Asia. Recommendations include the use of common regional screening methods and diagnostic criteria for GDM, generation of national and regional 
epidemiologic data on GDM prevalence and predisposing factors, and stimulation of local research to identify best practices for prevention and management of GDM in specific countries.

Acknowledgements The authors wish to acknowledge ILSI SEA staff Ms. Janice Lee and Ms. Jocelyn Wong for transcribing the oral presentations and discussion sessions.

Funding The symposium was funded by ILSI which is supported by its industry members.

Author contributions MSA wrote the initial and final drafts of the manuscript. SN presented a paper at the symposium and provided overall supervision, editing, and approval of the final version of the manuscript. MF-FC, VT, CS, JR, RI, HNKT presented individual papers at the symposium, provided feedback, and approved the final draft of the manuscript. All authors agree to be accountable for all aspects of the work in ensuring that questions related to the accuracy or integrity of any part of the work are appropriately investigated and resolved.

\section{Compliance with ethical standards}

Conflict of interest MSA and symposium speakers (MF-FC, VT, CS, JR, RI, HNKT, and SN) received funding for air travel, hotel, land transport, and meal allowances to attend the symposium held in Kuala Lumpur, Malaysia. No honoraria were received. The symposium is part of the activities of the ILSI SEA Maternal, Infant, and Young Child Nutrition Committee whose goal is to promote improvements in maternal, infant, and young child nutrition and health status in the Southeast Asia region. The authors declare no other conflict of interest. The funding organization had no role in the hypothesis/design, execution, analysis, or interpretation of materials presented in the paper and in the decision to submit for publication.

Publisher's note Springer Nature remains neutral with regard to jurisdictional claims in published maps and institutional affiliations.

Open Access This article is licensed under a Creative Commons Attribution 4.0 International License, which permits use, sharing, adaptation, distribution and reproduction in any medium or format, as long as you give appropriate credit to the original author(s) and the source, provide a link to the Creative Commons license, and indicate if changes were made. The images or other third party material in this article are included in the article's Creative Commons license, unless indicated otherwise in a credit line to the material. If material is not included in the article's Creative Commons license and your intended use is not permitted by statutory regulation or exceeds the permitted use, you will need to obtain permission directly from the copyright holder. To view a copy of this license, visit http://creativecommons. org/licenses/by/4.0/.

\section{References}

1. IDF International Diabetes Federation. IDF diabetes atlas. 9th ed. [Internet]. Brussels, Belgium: International Diabetes Federation. https://diabetesatlas.org/upload/resources/material/20200302_ 133351_IDFATLAS9e-final-web.pdf (2019). p. 168. Accessed 14 Feb 2020.

2. WHO. Diagnostic criteria and classification of hyperglycaemia first detected in pregnancy. Geneva: World Health Organization. https://apps.who.int/iris/bitstream/handle/10665/85975/WHO_ NMH_MND_13.2_eng.pdf;jsessionid=BAED6CF859571B 47CAB324FA5CA988D4? sequence $=1$ (2013). p. 62. Accessed 15 Mar 2020.

3. Purnamasari D, Waspadji S, Adam JMF, Rudijanto A. Tapahary $\mathrm{D}$ on behalf of the Indonesian Society of Endocrinology (ISE). Indonesian Clinical Practice Guidelines for diabetes in pregnancy. JAFES. 2013;28:9-13. https://doi.org/10.15605/jafes.028.01.02

4. Hirst JE, Tran TS, Do MAT, Morris JM, Jeffery HE Consequences of gestational diabetes in an urban hospital in Viet Nam: a prospective cohort study. PLoS Med. 2012; 9:e1001272. https://doi.org/10.1371/journal.pmed.1001272.

5. Bunthalarath S, Sunsaneevithayakul P, Boriboohirunsarn D. Risk factors for early diagnosis of gestational diabetes mellitus. J Med Assoc Thail. 2004;87(Suppl 3):S50-S53.

6. Lim-Uy SW, Cunanan EC, Andag-Silva AA. Prevalence and risk factors of gestational diabetes mellitus at the University of Santo Tomas Hospital. Philos J Int Med. 2010;48:24-31.

7. De Seymour J, Chia A, Colega M, Jones B, McKenzie E, Shirong $\mathrm{C}$, et al. Maternal dietary patterns and gestational diabetes mellitus in a multi-ethnic Asian cohort: the GUSTO study. Nutrients. 2016;8:pii.E574 https://doi.org/10.3390/nu8090574

8. Amiruddin R, Asrianti T, Tahir Abdullah M. Fiber, coffee, cigarette and gestational diabetes mellitus in Makassar Indonesia. Asian. J Epidemiol. 2017;10:26-31. https://doi.org/10.3923/aje.2017.26.31

9. Scott JM. Folate and vitamin B12. Proc Nutr Soc. 1999;58:441-8.

10. Wibowo N, Bardosono S, Irwinda R, Syafitri I, Putri AS, Prameswari N. Assessment of the nutrient intake and micronutrient status in the 1st trimester of pregnant women in Jakarta. Med J Indones. 2017;26:109-15.

11. Trang HNK, Yen TB, Tam TTN, Tuyet TD. Physical activity combine medical nutrition therapy to control glycemia gestational diabetes mellitus in Hung Vuong Hospital, Vietnam. J Gynecol Women's Health. 2019;15:555905 https://doi.org/10.19080/ JGWH.2019.15.555905.

12. Sunsaneevithayakul $\mathrm{P}$, Boriboohirunsarn $\mathrm{D}$, Sutanthavibul A, Ruangvutilert P, Kanokpongsakdi S, Singkiratana D, et al. Risk factor-based selective screening program for gestational diabetes mellitus Siriraj Hospital: result from clinical practice guideline. J Med Assoc Thail. 2003; 86:708-14.

13. Chen L-W, Lim AL, Colega M, Tint M-T, Aris IM, Tan CS, et al. Maternal folate status but not that of vitamins B-12 or B-6, is associated with gestational age and preterm birth risk in a multiethnic Asian population. J Nutr. 2015;145:113-20. https://doi.org/ 10.3945/jn.114.196352 